\title{
Extent of Pesticide Use and Application Practices in Small-Scale Farms of Kikome, Makueni County
}

\author{
Susan N. Dan ${ }^{1, *}$, Esther N. Kioko ${ }^{2}$ \\ ${ }^{1}$ Jomo Kenyatta University of Agriculture and Technology, Kenya. \\ ${ }^{2}$ Department of Zoology, National Museums of Kenya, Kenya.
}

How to cite this paper: Susan N. Dan, Esther N. Kioko. (2021) Extent of Pesticide Use and Application Practices in Small-Scale Farms of Kikome, Makueni County. International Journal of Food Science and Agriculture, 5(2), 241-250. DOI: 10.26855/ijfsa.2021.06.006

Received: February 23, 2021

Accepted: March 26, 2021

Published: April 23, 2021

*Corresponding author: Susan N. Dan, Jomo Kenyatta University of Agriculture and Technology, Kenya.

Email: sudanjeri@gmail.com

\begin{abstract}
Pesticides play a key role in agriculture by decreasing crop losses caused by insect pests. They increase crop production translating to national food security and contribute to improvement in human health by controlling disease vectors. Despite their role in controlling disease vectors, pesticides are toxic and have detrimental effects on human health, environment and biodiversity if used improperly. The present work reported findings of an assessment of pesticide use and application practices in Kikome village, Makueni County, Kenya. The major economic activity in this region is farming. Pests are problematic in this region due to high temperature that favors their growth and multiplication compelling farmers to use pesticides in their management. A survey involving 53 respondents, selected by purposive sampling, was carried out to assess pesticide use and application practices. Open ended questionnaires were administered through face to face interviews with the respondents. All the respondents interviewed during the study were using chemical pesticides as the sole method of pest management. Among various chemical compounds in the pesticides used by farmers, pyrethroid (87\%), neonicotinoid (69.6\%), and carbamate (63\%) based pesticides were the most frequently used. Farmers used pesticides more frequently at flowering stage (44\%) relative to other phenological stages. Most of the respondents (69.2\%) had no access to extension services. This study reported poor farmers' practices on pesticide use which threatens the diversity and abundance of insect pollinators.
\end{abstract}

\section{Keywords}

Survey, Farmers, Pesticides, Risks, Insect Pollinators, Biodiversity

\section{Introduction}

Biodiversity and associated ecosystem services are keys to human health [1]. Pollination is essential in provision of food and fibre, overall ecosystem resilience, aesthetics, and genetic diversity. Approximately, two thirds of crops feeding the world are insect pollinator dependent [2]. Reduced crop yield and misshapen fruits are caused by inadequate pollination and not necessarily inadequate agricultural inputs [3]. Pests are major causes of crop yield and quality reductions in that they contribute to endemic poverty mostly in the developing countries [4]. They are key inputs in agricultural production in reducing crop losses due to infestation by pests and diseases. Pesticides are toxic and cause environmental pollution and death of beneficial organisms such as insect pollinators [4]. Unexpected environmental contamination has resulted from use of very toxic pesticides, inadequate management and poor handling practices [5]. Carbamate based pesticides are toxic to parasitic wasps and bees [6]. Although organosulphates are easily hydrolysed, they are highly toxic to invertebrates and insects [7]. Majority of farmers in Eastern Kenya using pesticides do not manage pollination in any way and use pesticides as sole method of pest control [4]. The present study seeks to assess the extent of pesticides use and application practices in Kikome village in Makueni County and their potential detrimental effects on diversity and abundance of insect pollinators in Kikome, Makueni County. 


\section{Materials and methods}

\subsection{Description of the study area}

The study was conducted in Kikome village, Makueni-Eastern Kenya (S 02.14504 ${ }^{\circ}$, E 037. 80262 ${ }^{\circ}$, and elevation 803m above sea level) between the month of September and October, in 2017. The village is in the arid and semi-arid zones of Eastern Kenya. Soils are usually sandy characterized by a $\mathrm{pH}$ range of 5.1 to 7.2 and low to moderate organic matter content (0.43 \%-1.87 \% TOC). The area is characterized by dense bushes, shrubs and wild trees. The area experiences a bimodal type of rainfall with short rains in November/December and long rains in March/April. The area experiences high temperatures of $35.8^{\circ} \mathrm{C}$ and high rate of evaporation. Generally, high temperatures are experienced during the day and low temperatures at night.

\subsection{Study design}

The instrument for the survey was a questionnaire which was designed using information sourced from literature review. A pilot test was done before the actual survey to ensure that the questionnaire was adequate in obtaining the required information. The questionnaire had both open and close-ended questions. Pre-visits were done to familiarize with the study area, discuss with the relevant authority (chief, area in charge and village elders) and inform the respondents of the intended exercise and its purpose. The study population was comprised of horticulture farmers in Kikome village and was determined using procedures established by equation 1 [8]. A total of 53 respondents were involved in the survey using the formulae:

$$
n f=\frac{N}{1+\frac{N}{\text { POPULATION }}} \quad \text { Equation } 1
$$

Where $\mathrm{N}$ is the known population, $\mathrm{n}$ is the sample size.

Out of the 53 respondents, 7 did not answer the questions correctly and were therefore excluded from data analysis. Therefore, only data from 46 respondents were considered for analysis.

\subsection{Data collection}

The questionnaire was administered to individuals within households who used pesticides and not necessarily the farm owners. The respondents were selected by purposive sampling method. A standardized questionnaire was used as a measurement tool and consisted of (1) socio-demographic characteristics as age, gender, and level of education, (2) information regarding pesticides use in controlling common pests, the common crops, major problematic pests and the types of pesticides that they used in pest management, (3) practices on using pesticides, including time of the day and cropping stage that respondents applied pesticides more frequently. Information on whether farmers received any training on pesticides use and application practices were also gathered.

\subsection{Data analysis techniques}

Quantitative data collected was analyzed using descriptive statistical techniques that were frequencies, percentages, and standard errors. This was done using the statistical package for Social sciences (SPSS) version 22 [9]. In regards to qualitative data, farmers were allowed to list their responses in an open-ended format and later analyzed using statistical techniques which includes frequencies, percentages and standard errors using SPSS version 22. The multinomial logit model was used to estimate the factors that determined farmers' choices in using and applying chemical pesticides. Estimated coefficients were compared with the base category. The likelihood ratio statistics were indicated by the Chi-square test and checked if it was significant statistically. The Hausman's specifications test procedure was used to check the validity of the model of the independence of the irrelevant alternatives.

\section{Results}

\subsection{Characteristics of the study population}

The characteristics of respondents within the study area are given in Table 1 . About 69.6\% of the respondents were male while 30.4 \% were female. The majority of respondents were young people aged between 34-41 years (26.1\%). Most respondents had acquired primary level of education (52.2\%), while the least had attained college/university level of education (15.2\%) (see Table 1$)$. 
Table 1. Characteristics of the study population

\begin{tabular}{ccc}
\hline Demographic aspect & Frequency (n) & Proportion (\%) \\
\hline Gender & 32 & 69.6 \\
Male & 14 & 30.4 \\
Female & 46 & 100 \\
Total & & \\
Age brackets & 4 & 8.7 \\
$18-25$ & 11 & 23.9 \\
$26-33$ & 12 & 26.1 \\
$34-41$ & 6 & 13.0 \\
$42-49$ & 9 & 19.6 \\
$50-57$ & 4 & 8.7 \\
$>58$ & 46 & 100 \\
Total & & 52.2 \\
Level of education & 24 & 32.6 \\
Primary & 15 & 15.2 \\
Secondary. & 7 & 100.0 \\
University/college & 46 & \\
Total &
\end{tabular}

\subsection{Common crops grown and the common arthropod pests within the area}

There was a wide diversity of crops grown within the County (Figure 1). The most commonly crops grown include cowpea, maize, green grams and sorghum in increasing order of importance. Cowpea was the most commonly grown (91\% of all crops grown in the study area) (Figure 1). The least commonly grown crops were coriander, Amaranthus sp, pumpkin and cucumber.

The study also reported a diverse population of arthropod pests within the study area (Figure 2). The most problematic pest reported affecting crop production was whiteflies (84.6\%) while the diamondback moth was the least problematic (2.2\%) (Figure 2).

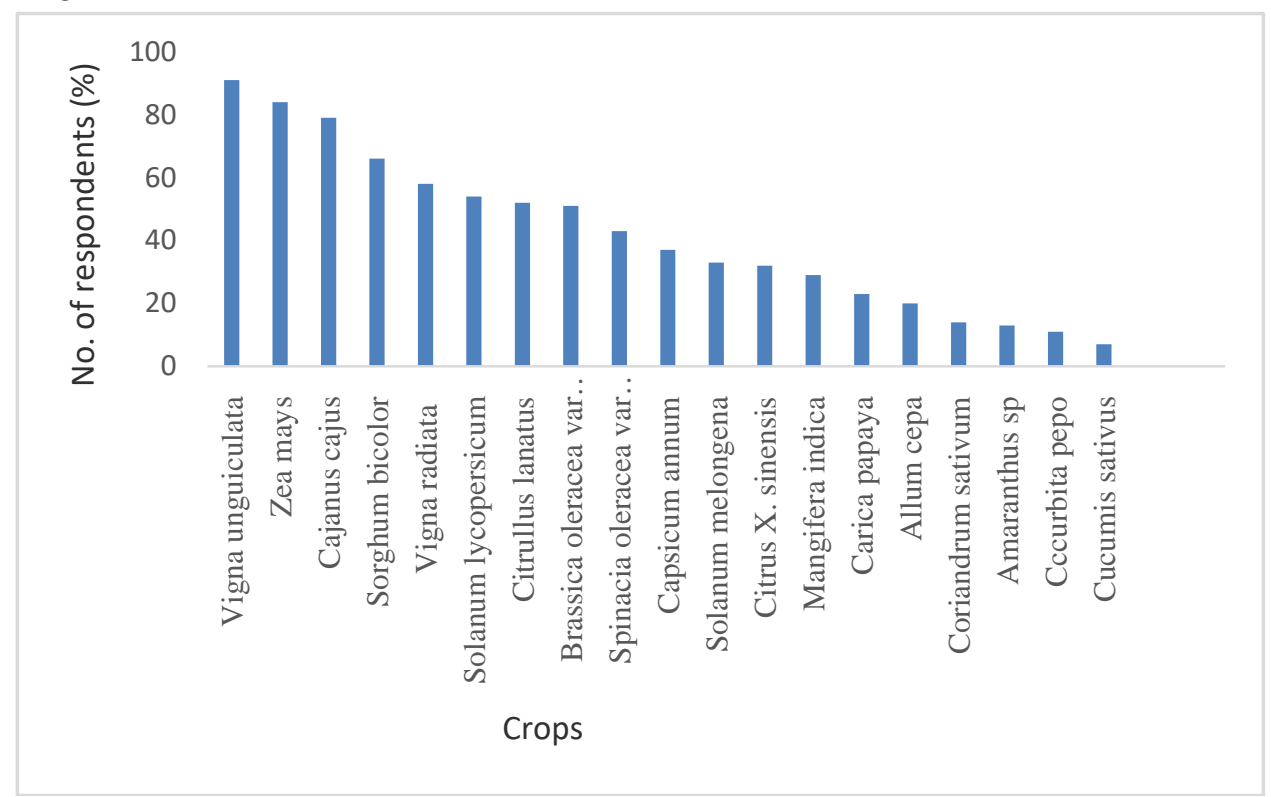

Figure 1. Common crops grown within Kikome village, Makueni County. 


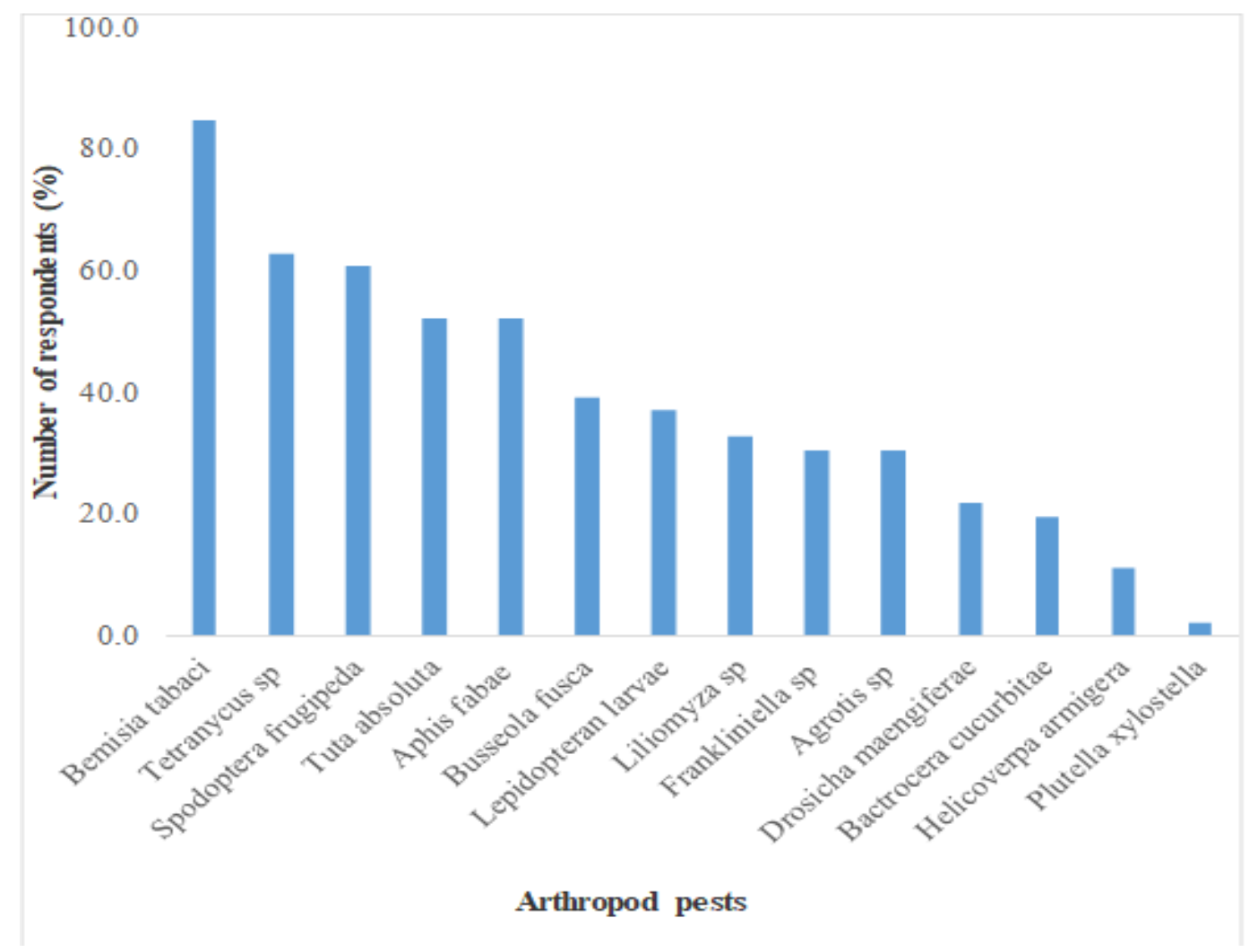

Figure 2. Arthropod pests encountered by farmers in Kikome, Makueni County.

\subsection{Pesticides used within the study area}

All the respondents interviewed during the survey were using chemical pesticides in pest management. A total of 41 pesticides belonging to 14 chemical groups were recorded. Pyrethroid (87\%), carbamate (69.6\%) and neonicotinoid (63\%) based pesticides were the most frequently used (Table 2). In addition, 58.7\% of the pesticides used belonged to WHO class II while Class IV pesticides were the least used (15.2\%) (Figure3).

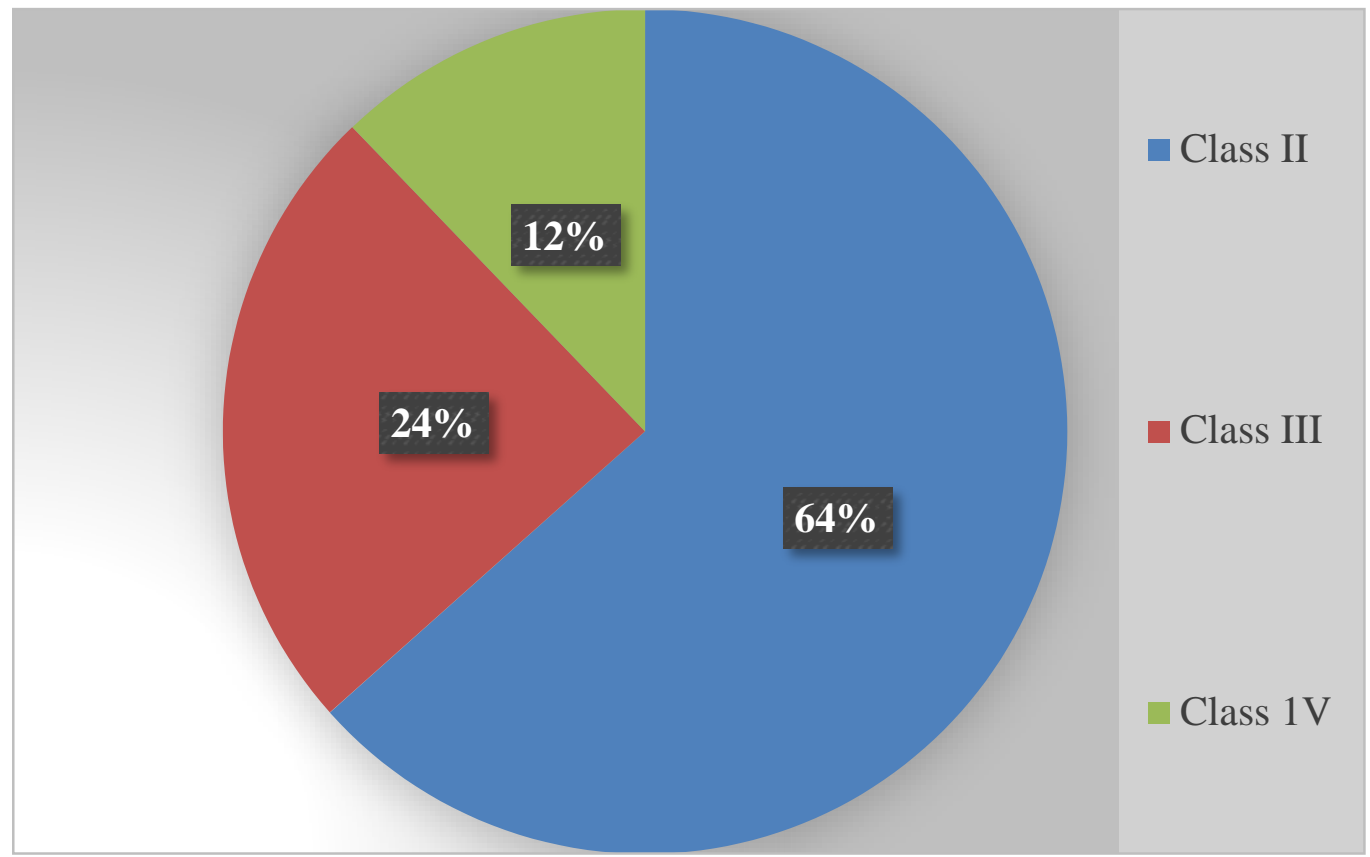

Figure 3. WHO classification of the commonly used pesticides within Kikome, Makueni County. 
Table 2. Pesticides used within Kikome, Makueni-Eastern Kenya

\begin{tabular}{|c|c|c|c|c|c|}
\hline $\mathrm{S} / \mathbf{N}$ & Chemical class & $\begin{array}{c}\% \\
\text { use } \\
\end{array}$ & Pesticide & ActiveIngredient & $\begin{array}{l}\text { WHO } \\
\text { Class } \\
\end{array}$ \\
\hline \multirow[t]{11}{*}{1} & \multirow[t]{11}{*}{ Pyrethroid } & \multirow[t]{11}{*}{87} & Karate $^{\mathrm{I}}$ & $\begin{array}{c}\text { Lambda } \\
\text { Cyhalothrin }\end{array}$ & II \\
\hline & & & Pentagon ${ }^{\mathrm{I}}$ & $\begin{array}{l}\text { Lambda } \\
\text { Cylohathrin }\end{array}$ & II \\
\hline & & & Duduthrin $^{\mathrm{I}}$ & $\begin{array}{l}\text { Lambda } \\
\text { Cylohathrin }\end{array}$ & II \\
\hline & & & Engeo $^{\mathrm{I}}$ & $\begin{array}{l}\text { Lambda } \\
\text { Cylohathrin }\end{array}$ & II \\
\hline & & & Tornado ${ }^{\mathrm{I}}$ & $\begin{array}{c}\text { Lambda } \\
\text { Cyhalothrin }\end{array}$ & II \\
\hline & & & Tata alpha ${ }^{\mathrm{I}}$ & Alphacypermethrin & II \\
\hline & & & Profile ${ }^{\mathrm{I}}$ & Alphacypermethrin & II \\
\hline & & & Bestox $^{I}$ & Alphacypermethrin & II \\
\hline & & & Atom $^{\mathrm{I}}$ & Deltamethrin & II \\
\hline & & & Cyclone $^{\mathrm{I}}$ & Cypermethrin & II \\
\hline & & & Betafos $^{I}$ & Beta cyfluthrin & II \\
\hline \multirow[t]{8}{*}{2} & \multirow[t]{8}{*}{ Carbamate } & \multirow[t]{8}{*}{69.6} & Antracol $^{\mathrm{F}}$ & Propineb & $1 \mathrm{~V}$ \\
\hline & & & Antracol $^{\mathrm{F}}$ & Propineb & IV \\
\hline & & & Merit $^{\mathrm{I}}$ & Indioxacarb & III \\
\hline & & & $\begin{array}{l}\text { Ridomi }^{\mathrm{I}} \\
\text { Gold }^{\mathrm{F}}\end{array}$ & Metalaxyl & III \\
\hline & & & $\begin{array}{l}\text { Milthane } \\
\text { super }^{\mathrm{F}}\end{array}$ & Mancozeb & IV \\
\hline & & & Dithane ${ }^{\mathrm{F}}$ & Mancozeb & III \\
\hline & & & EMthane $\mathrm{M} 45^{\mathrm{F}}$ & Mancozeb & IV \\
\hline & & & Dithane $\mathrm{M} 45^{\mathrm{F}}$ & Mancozeb & IV \\
\hline \multirow[t]{6}{*}{3} & \multirow[t]{6}{*}{ Neonicotinoid } & \multirow[t]{6}{*}{63} & Actara & Thiamethoxam & III \\
\hline & & & Engeo $^{\mathrm{I}}$ & Thiamethoxam & II \\
\hline & & & Prosper $^{\mathrm{F}}$ & Clothianidin & II \\
\hline & & & Presento ${ }^{\mathrm{I}}$ & Acetamiprid & II \\
\hline & & & Thunder ${ }^{\mathrm{I}}$ & Imidacloprid & II \\
\hline & & & Confidor $^{\mathrm{I}}$ & Imidacloprid & II \\
\hline \multirow[t]{5}{*}{4} & \multirow[t]{5}{*}{ Strobilurins } & \multirow[t]{5}{*}{26.1} & Ortiva $^{\mathrm{F}}$ & Azoxystrobin & II \\
\hline & & & Prosper ${ }^{\mathrm{F}}$ & Triflocystrobin & II \\
\hline & & & Nativo $^{\mathrm{F}}$ & Tryfloxystrobin & III \\
\hline & & & Nativo $^{\mathrm{F}}$ & Tebuconazole & III \\
\hline & & & Ortiva $^{\mathrm{F}}$ & Difenoconazole & II \\
\hline \multirow[t]{4}{*}{5.} & \multirow[t]{4}{*}{ Avermectin } & \multirow[t]{4}{*}{60.2} & Alonze $^{\mathrm{I}}$ & Abamectin & II \\
\hline & & & Dynamic $^{\mathrm{I}}$ & Abamectin & II \\
\hline & & & Romectin $^{\mathrm{I}}$ & Abamectin & II \\
\hline & & & Prove $^{\mathrm{I}}$ & Emamectine Benzoate & II \\
\hline \multirow[t]{3}{*}{6} & \multirow[t]{3}{*}{ Inorganics } & \multirow[t]{3}{*}{21.7} & Thiovit $^{\mathrm{F}}$ & Sulfur & II \\
\hline & & & Amicop $^{\mathrm{F}}$ & Copper oxychloride & II \\
\hline & & & Funguran ${ }^{\mathrm{F}}$ & Copper hydroxide & II \\
\hline \multirow[t]{3}{*}{7} & \multirow[t]{3}{*}{ Organophosphate } & \multirow[t]{3}{*}{19.6} & Dithane $\mathrm{M} 45^{\mathrm{F}}$ & Chlorpyrifos & IV \\
\hline & & & Betafos $^{\mathrm{I}}$ & Chlorpyrifos & II \\
\hline & & & Oshothion $^{\mathrm{I}}$ & Malathion & II \\
\hline 8 & Triazole & 19.6 & Score ${ }^{\mathrm{F}}$ & Difenoconazole & III \\
\hline 9 & Phthalicacid diamides & 34.8 & Belt $^{\mathrm{I}}$ & Flubendiamide & III \\
\hline 10 & $\begin{array}{l}\text { Sulfonylaminocar } \\
\text { bonyl-triazoniline }\end{array}$ & 8.7 & Attribute $^{\mathrm{H}}$ & $\begin{array}{c}\text { Propoxycarbazone- } \\
\text { Sodium }\end{array}$ & II \\
\hline 11 & Benzimidazole & 17.4 & Chariot $^{\mathrm{F}}$ & Carbendazim & II \\
\hline 12 & Sulfooarbaide & 10.9 & Pegasus ${ }^{I}$ & Diafenthiuron & III \\
\hline 13 & Acylamines & 30.4 & Ridomil Gold ${ }^{\mathrm{F}}$ & Mancozeb & II \\
\hline 14 & $\begin{array}{l}\text { Anthranilic } \\
\text { diamide }\end{array}$ & 34.8 & Coragen $^{\mathrm{I}}$ & Chlorantraniliprole & IV \\
\hline
\end{tabular}

I = Insecticide, $\mathrm{F}$ = Fungicide, $\mathrm{H}=$ Herbicide. 


\subsection{Pesticide application practices}

The number of respondents who applied pesticides in the morning was twice (13\%) higher than those who applied in the evening (6\%). About $17 \%$ of the respondents chose either a morning or evening spraying regime. In addition, $10 \%$ of respondents applied pesticides at any time of the day (Figure 4).

About $44 \%$ of the respondents applied pesticides more frequently at the flowering stage while a few number (3\%) applied pesticides frequently in all stages of production (Figure 5). Other respondents applied pesticides frequently during the germination, vegetative, budding, and fruit set stage. Most of the respondents (69.2\%) had no access to extension services and were not trained on pesticide use and application practices (Figure 6).

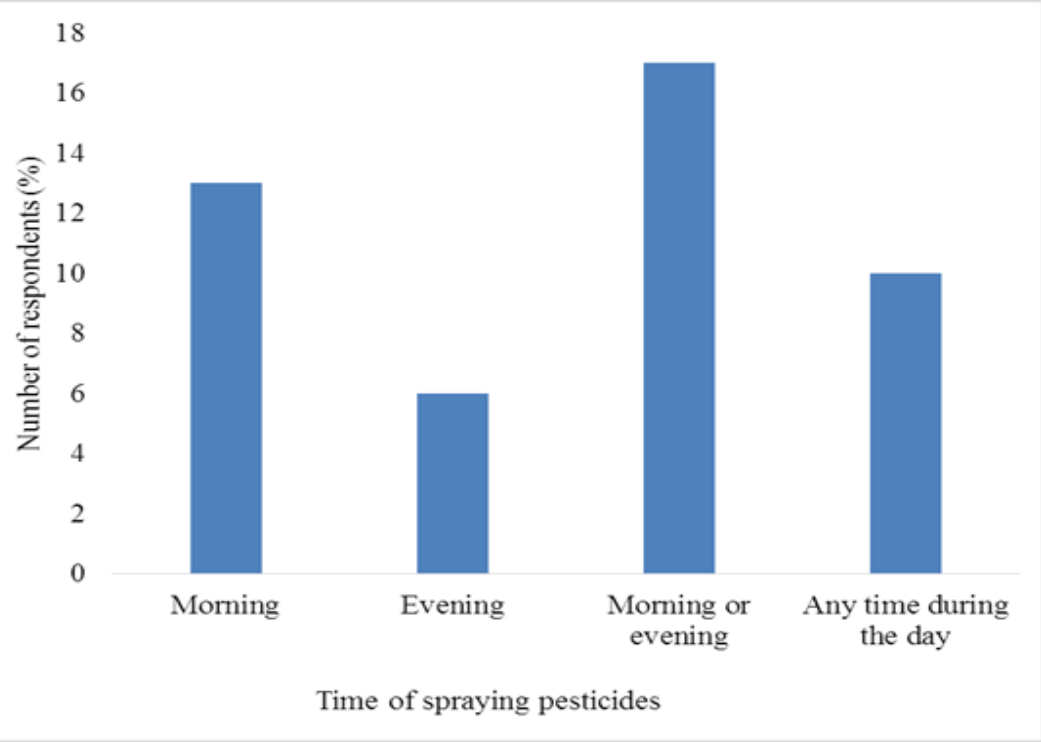

Figure 4. Time of the day of spraying pesticides.

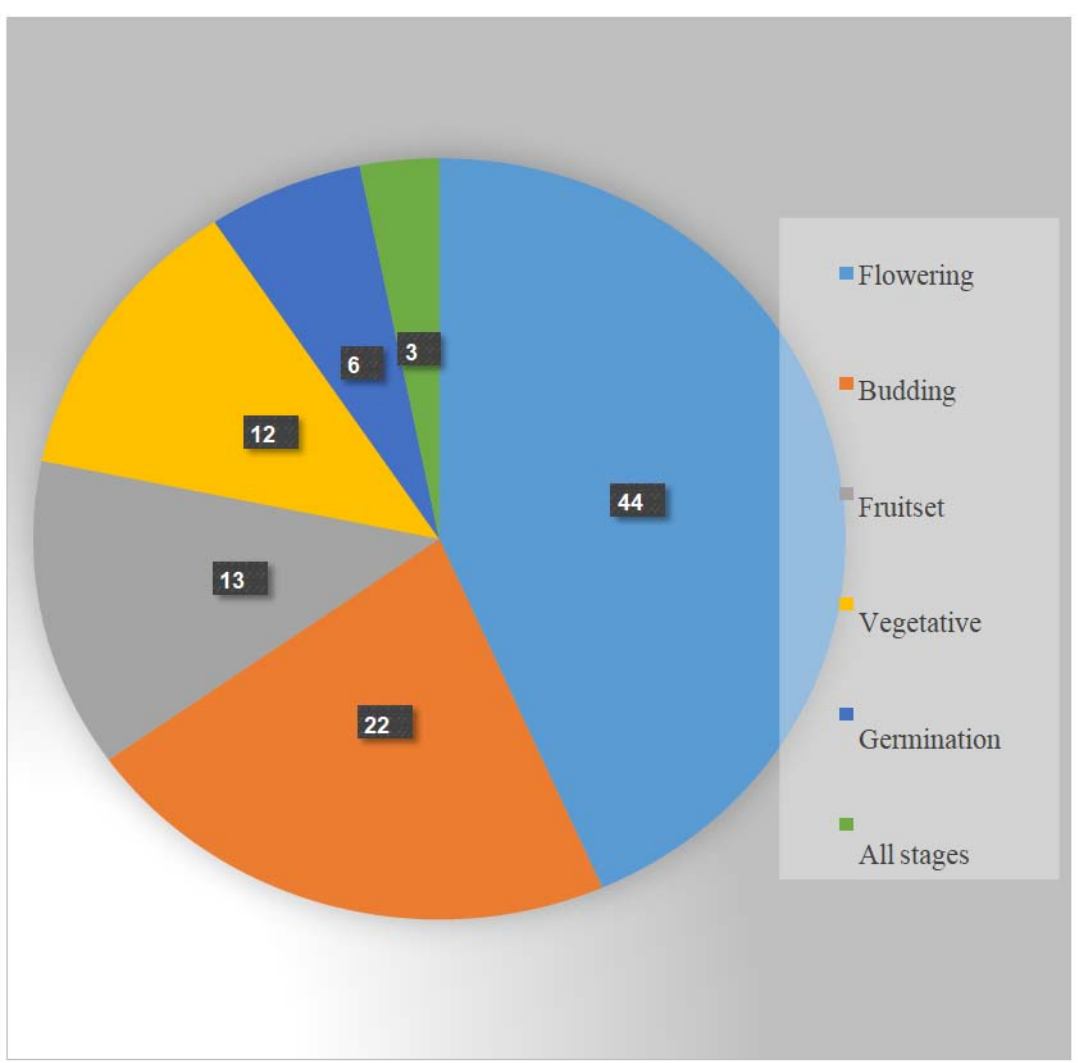

Figure 5. Cropping stage when farmers applied pesticides more frequently. 


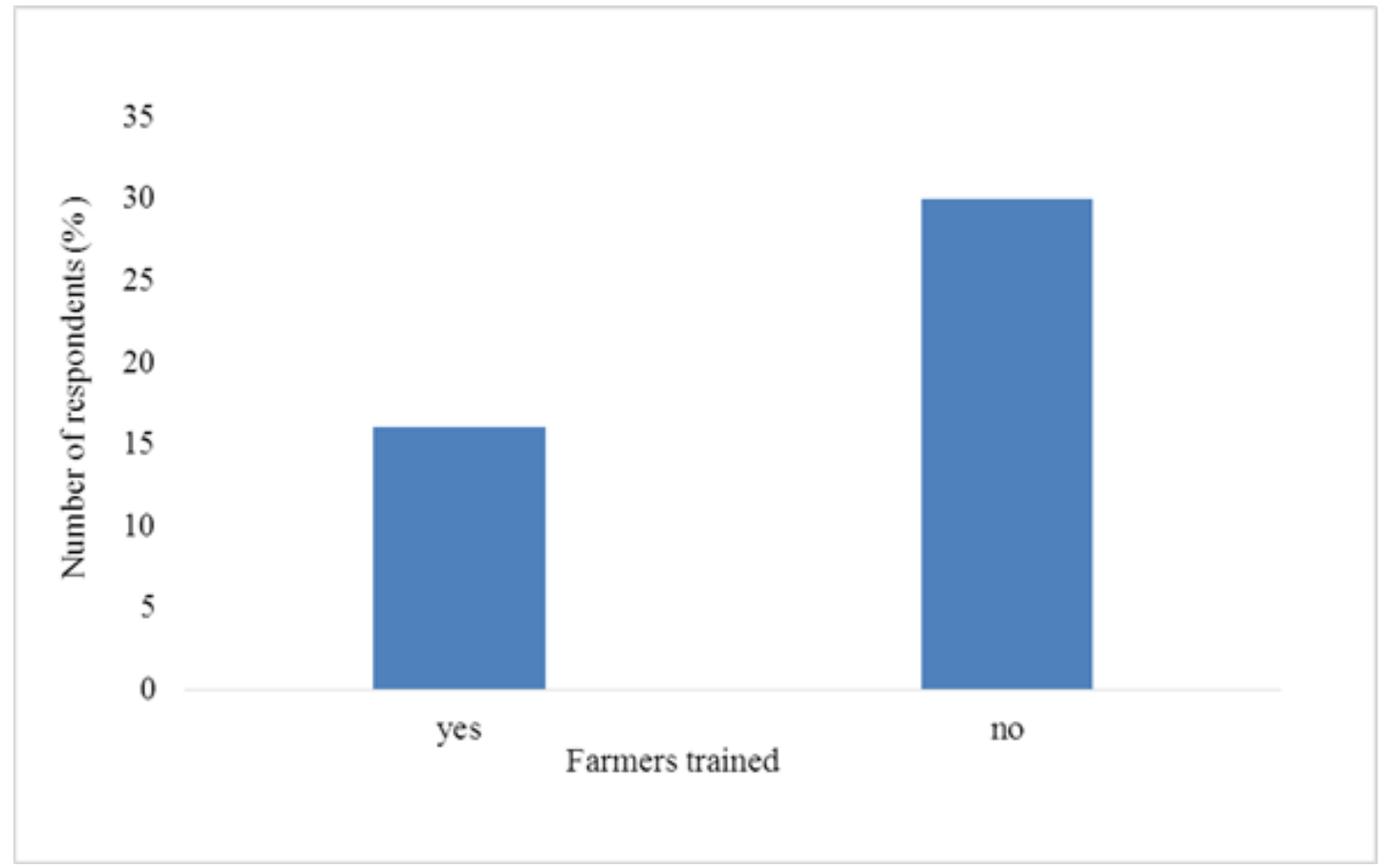

Figure 6. Farmers trained on pesticide use and safety.

\subsection{Determinants of farmers' choices in pesticide use and application practices}

Different social economic characteristics are important for their consideration in their potential to influence the proper use or misuse of pesticides.

\subsubsection{Time of spraying pesticides}

The multinomial regression model was found to be significant $(X 2=46)$, d.f $=27, \mathrm{p}=0.013)$, and explained $68.1 \%$ of variation of spraying time as explained by gender, age, education level (Table 3). Education and age were found to significantly influence time of spraying but gender of farmers did not have any impact (Table 4).

Table 3. Model Fitting Information

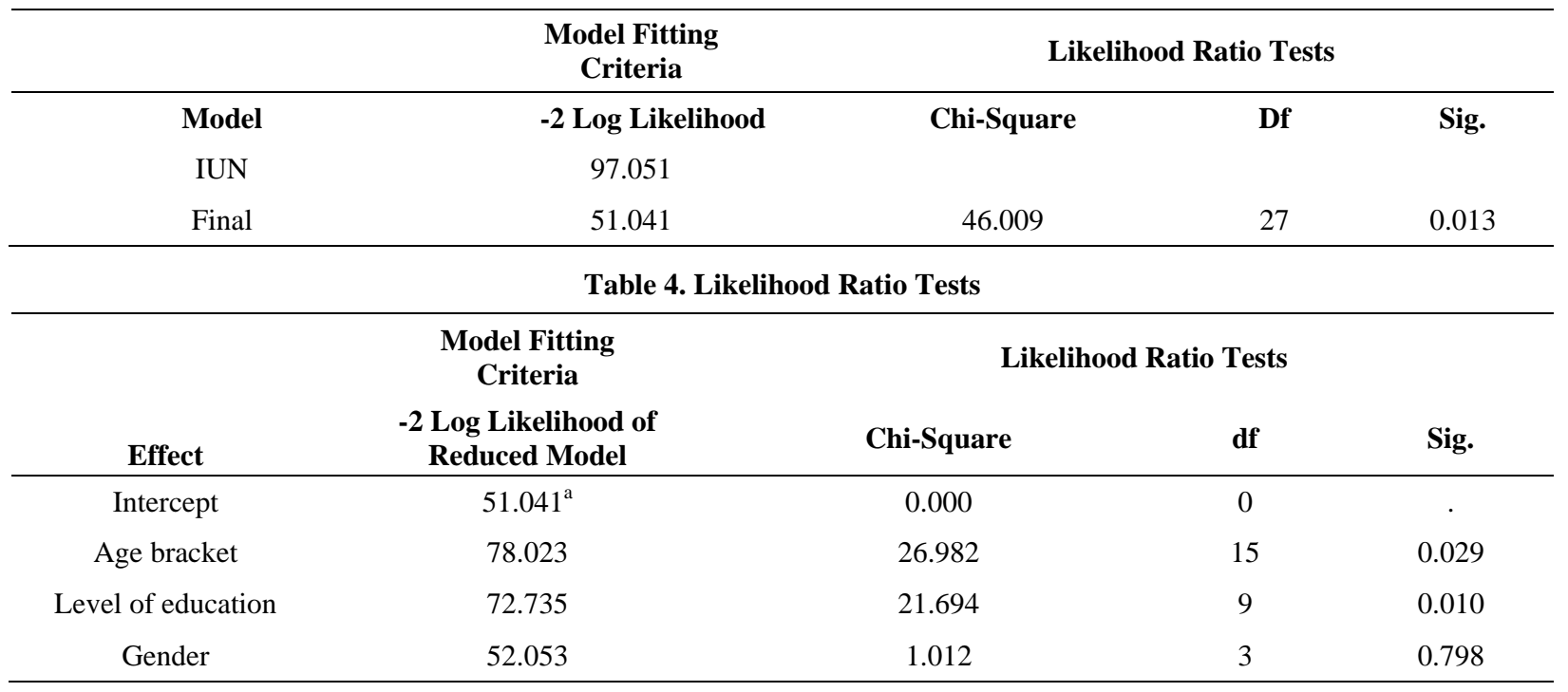

\subsubsection{Cropping stage when farmers frequently used pesticides}

The multinomial regression model was found to be significant $(X 2=79)$, d.f $=45, p=0.001)$, and explained 86\% of variation of the cropping stage when farmers frequently applied pesticides as explained by gender, age, education level (Table 5). The age, level of education and gender were found to significantly influence time of spraying (Table 6). 
Table 5. Model Fitting Information

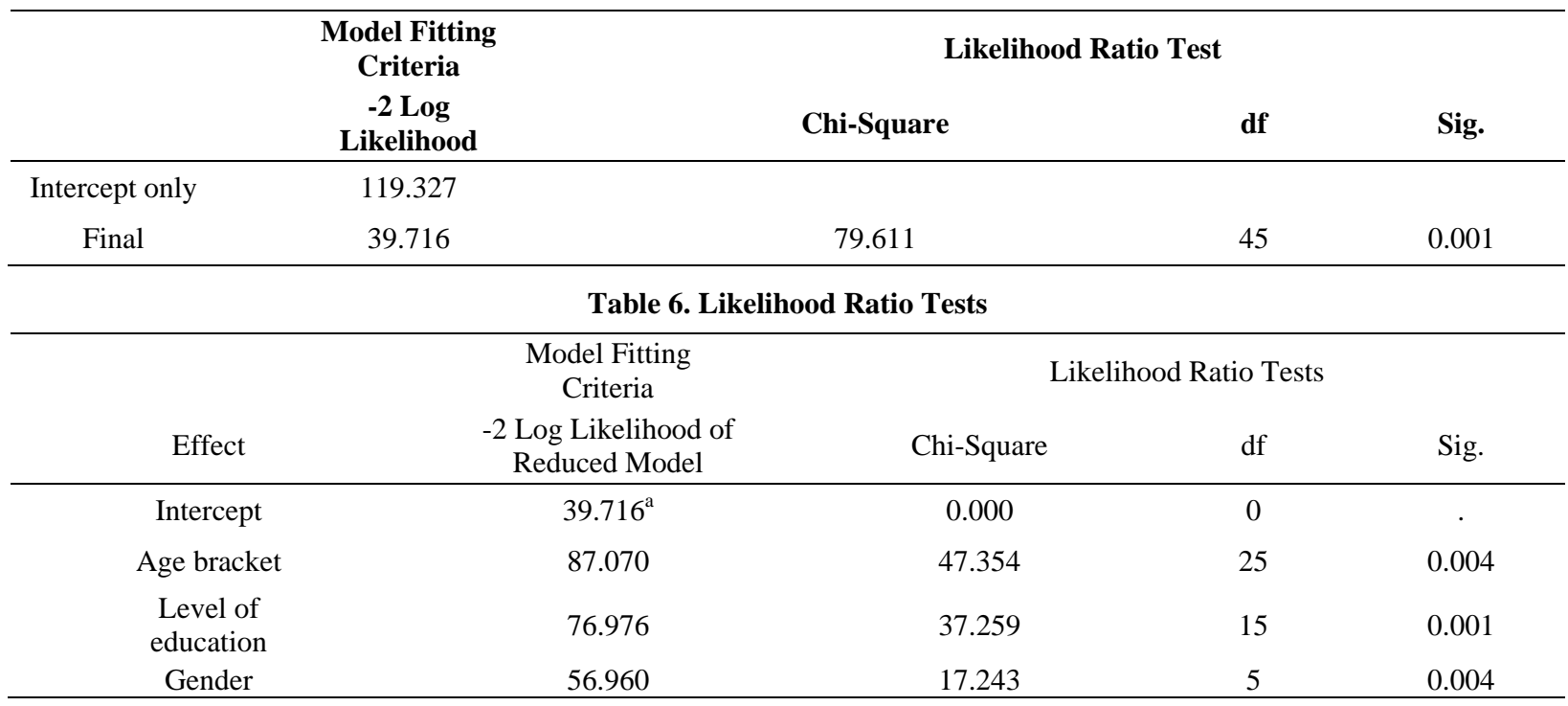

\section{Discussion}

Gender is an important aspect influencing social practices as each gender has hyper sensitivities that are hormonally controlled [10]. Previous studies have indicated that spraying of pesticides is mainly done by men who also decide on what pesticides to spray [11].

Majority of the respondents in this study were young people aged between 34-41 years. Age is an important factor influencing decision making [12], as young people in farming tends to be flexible in decision making and the ability to adopt new technologies. Previous studies also reported that old people did not trust any new technology, as well as adopting safe handling methods in pesticide use [12]. The same authors also observed that old farmers were conservative and held onto their past convectional practices as the use of DDT (Dichlorodiphenyltrichloroethane) due to the earlier gains in inputs associated with its use.

Majority of respondents in this study had acquired primary level of education, while the least had attained university/college level. Education has positive impact on farmers' lifestyles [13]. Educated farmers have an ability to understand effects of pesticides on human health and environment [14]. It is encouraging that $15.2 \%$ of respondents had received college/university education. Such a category of farmers would need little exposure in pollinator conservation issues to enable them to embrace good agricultural practices that are biodiversity friendly. Having the majority of farmers with low levels of education is a major concern [15]. This is because such farmers may not understand the scientific principles of insect pollination and implications of indiscriminate use of chemical pesticides on insect pollinators. As a result, they may engage in pest control practices that have detrimental effects on insect pollinators interfering with benefits associated with them.

All the respondents interviewed during the survey used chemical pesticides in pest management. Previous studies among smallholder vegetable farmers in Ethiopian Central Rift Valley also reported that all respondents were using chemical pesticides as the sole method of pest management [11]. The authors observed that no IPM strategy or biological control was being used by farmers neither were the principles fully understood.

In another study, it was recorded that $98.6 \%$ of respondents used pesticides solely in the management of tomato pests in Kathiani District, Kenya [16]. The authors reported 19 chemical pesticides containing 21 chemical compounds with carbamates, pyrethroids and organophosphates being the most frequently used. Besides, Class II pesticides were the most frequently used (68.4\%) followed by class IV (21.1\%) and class III (10.5\%).

In the assessment of farmers' knowledge on pesticide use within smallholder potato farms in Uganda, it was reported that all respondents in South-Eastern highlands were using chemical pesticides in pest management majorly fungicides and insecticides [17].

Majority of the respondents in the present study were using pesticides more frequently during the flowering period. A study was conducted at both pre-flowering and flowering stage to compare the impacts of Dimethoate (organophosphate) and lambda-cyhalothrin (pyrethroid) on sunflower pollination and associated yield in Eastern Kenya [4]. The authors observed that plots treated with insecticides recorded a lower number of developed seeds, of smaller size and lower weight than the control (untreated plots). In addition, the plots that were treated with dimethoate (organophosphate) recorded a lower number offoraging bees relative to plots sprayed with lambda-cyhalothrin (pyrethroid). They recom- 
mended that farmers should adopt pest management practices that are bee-friendly.

The majority of respondents applied pesticides either in the morning or evening. This shows that they were informed on the best time of the day when pesticides should be applied. Applications made either early in the morning or late evening minimizes exposure of insect pollinators to pesticides since the floral resources are depleted and the foraging activity of diurnal insect pollinators is low [18]. Evening applications are safer because of the longer exposure period before diurnal insect pollinators visit the crop [19]. Previous studies indicated that evening insecticide applications, even at the flowering stage, reduced negative impacts of pesticides on the foraging activities of the honey bees [4]. In addition, the authors recorded more yield in plots treated with insecticides in the evening than in the morning.

In Ethiopia, previous studies reported that the respondents did not fully understand the environmental effects of pesticides [20]. Majority of farmers were unable to read pesticide labels which could provide instructions for use since the label was written in foreign language or the letter font was too small.

The majority of respondents in the present study had no access to extension services on pesticides use and safety. This agrees with studies done elsewhere. In a survey to assess the impacts of training farmers on pesticide use and application practices in Greece, the authors observed that farmers' knowledge and beliefs in pesticide hazard control correlated with safety compliance [21].

Poor practices in using chemical pesticides as well as application practices in the present study can be attributed to farmers' lack of adequate technical knowledge and training on pesticide use and application practices. All stakeholders including environmental Non-Governmental Organization, agrochemical industry, extension workers and health practitioners should provide technical support to farmers to address the existing knowledge gaps.

Training farmers has proved useful in changing farmers' mind set in using and applying chemical pesticides [22, 23]. This is because pesticides are complex, hazardous and toxic. Also, small scale farmers may find the information provided on the label to be very technical to understand. Farmers would therefore need technical support from both state and non-state actors for correct pesticide use and application practices.

Lack of training on pesticide safety is the possible reason why the principles of biodiversity conservation are not put into consideration during pest management. As such, farmers have a mindset that chemical pesticides have a quick knockdown effect hence their preference. Moreover, methods of pest management such as biological control and IPM (Integrated Pest Management) are not fully understood by farmers.

\section{Conclusions}

There is overreliance on the use of chemical pesticides as all respondents were using chemical pesticides as the sole method of pest management. There was frequent use of relatively toxic chemical group of pesticides mostly the pyrethroid, carbamate and neonicotinoid based pesticides during the flowering stage which is a risk to the insect pollinators feeding on the nectar and pollen.

The study recommends further studies on the effects of the most frequently used chemical pesticides and application practices on the diversity and abundance of insect pollinators.

\section{Acknowledgement}

We sincerely thank the National Museums of Kenya and the Bayer Bee Care Germany who funded the research work.

\section{References}

[1] Assessment, M. E. (2005). Ecosystems and human well-being (Vol. 5). Washington, DC: Island press.

[2] FAO. (2008). Food and Agriculture Organization of the United Nations. An introduction to the basic concepts of food security. Rome.

[3] Kwapong, P. (2008). African Pollinator Initiative (API). Global Bee Summit, Durban South Africa. In Workshop Presentation.

[4] Nderitu, J., Kasina, M., Nyamasyo, G., and Oronje, M. L. (2007). Effects of insecticide applications on sunflower (Helianthus annuus L.) pollination in Eastern Kenya. World Journal of Agricultural Sciences, 3(6), 731-734.

[5] Ntow, W. J., Gijzen, H. J., Kelderman, P., and Drechsel, P. (2006). Farmer perceptions and pesticide use practices in vegetable production in Ghana. Pest Management Science: formerly Pesticide Science, 62(4), 356-365.

[6] Liu, Z., Liu, W., Rao, H., Feng, T., Li, C., Wang, C., and Wang, Z. (2012). Determination of some carbamate pesticides in watermelon and tomato samples by dispersive liquid-liquid micro extraction combined with high performance liquid chromatography. International Journal of Environmental Analytical Chemistry. Taylor and Francis publisher. London, 92(5), 571-581.

[7] Anderson, T. D. and Lydy, M. J. (2002). Increased toxicity to invertebrates associated with a mixture of atrazine and organophosphate insecticides. Environmental Toxicology and Chemistry: An International Journal, 21(7), 1507-151.

[8] Whitley, E. and Ball, J. (2002). Statistics review 4: sample size calculations. Critical care, 6(4), 335. 
[9] Corp, I. B. M. (2013). IBM SPSS statistics for windows, version 22.0. Armonk, NY: IBM Corp.

[10] Duah, A. (2002). Public health assessment for human exposure to chemicals.

[11] Mengistie, B. T., Mol, A. P., and Oosterveer, P. (2017). Pesticide use practices among smallholder vegetable farmers in Ethiopian Central Rift Valley. Environment, Development and Sustainability, 19(1), 301-324.

[12] de Acedo Liza'́rraga, M. S., de Acedo Baquedano, M. S., and Cardelle-Elawar, M. (2007). Factors that affect decision making: Gender and age differences. International Journal of Psychology and Psychological Therapy, 7(3), 381-391.

[13] Ríos-González, A., Jansen, K., and Sánchez-Pérez, H. J. (2013). Pesticide risk perceptions and the differences between farmers and extensionists: Towards a knowledge-in-context model. Environmental research, 124, 43-53.

[14] Karlsson, S. I. (2004). Agricultural pesticides in developing countries. Environment, 46(4), 22.

[15] Hordzi, W. (2015). The Mix of Physics, Chemistry and Biology: Preference and Performance of Distance Education Students in Science. 92

[16] Mutuku, M., Njogu, P., and Nyaga, G. (2014). Assessment of pesticide use and application practices in tomato based Agrosystems in Kaliluni sub location, Kathiani District, Kenya. Journal of Agriculture, Science and Technology, 16(2).

[17] Okonya, J. S. and Kroschel, J. (2015). A cross-sectional study of pesticide use and knowledge of smallholder potato farmers in Uganda. BioMed research international, 2015.

[18] Jonathan, L., Adam, D., David, H., Benjamin, M., Douglas, S., Richmond, Williamson, R. (2017). Optimizing Pest Management Practices to Conserve Pollinators in Turf Landscapes: Current Practices and Future Research Needs. Integrated Pest Management, 8(1): 18, 1-10.

[19] Abrol, D. P. (2012). Safety of Pollinators. In Pollination Biology (311-352). Springer, Dordrecht.

[20] Jansen, H. C. and Harmsen, J. (2011). Pesticide monitoring in the Central Rift Valley 2009-2010: ecosystems for water in Ethiopia (No. 2083). Alterra.

[21] Damalas, C. A. and Koutroubas, S. D. (2017). Farmers' training on pesticide use is associated with elevated safety behavior. Toxics, 5(3), 19.

[22] Van den Berg, H., Jiggins, J., (2007). Investing in farmers - the impacts of farmer field schools in relation to integrated pest management. World Development. 35(4), $663 e 686$.

[23] Gautam, S., Schreinemachers, P., Uddin, M. N., and Srinivasan, R. (2017). Impact of training vegetable farmers in Bangladesh in integrated pest management (IPM). Crop protection, 102, 161-169. 